\title{
Assessment of contraceptive vaccines based on recombinant mouse sperm protein $\mathrm{PH} 20$
}

\author{
Christopher M Hardy, Gavin Clydesdale, Karen J Mobbs, Jenny Pekin, Megan L Lloyd', \\ Clive Sweet $^{2}$, Geoffrey R Shellam ${ }^{1}$ and Malcolm A Lawson ${ }^{1}$ \\ Pest Animal Control Cooperative Research Centre, CSIRO Sustainable Ecosystems, GPO Box 284, Canberra, \\ ACT 2601, Australia, ${ }^{1}$ Microbiology, School of Biomedical and Chemical Sciences, M502 University of Western \\ Australia, 35 Stirling Highway, Crawley, WA 6009, Australia and ${ }^{2}$ School of Biosciences, University of \\ Birmingham, Edgbaston, Birmingham B15 2TT, UK
}

Correspondence should be addressed to Chris Hardy; Email: chris.hardy@csiro.au

\begin{abstract}
Mouse PH20 (mPH20), the mouse homologue to guinea pig hyaluronidase protein PH20 (gpPH20), was used to produce contraceptive vaccines that target both sexes of mice. Previously, immunization with a female gamete antigen (the zona pellucida subunit 3 protein) delivered in a recombinant murine cytomegalovirus (MCMV), or as a purified recombinant protein, has been shown to induce infertility in female mice. There is evidence, however, that sperm protein antigens could provide broader contraceptive coverage by affecting both males and females, and the most promising has been gpPH20 when tested in a guinea pig model. Mice were therefore either inoculated with a recombinant MCMV expressing $\mathrm{mPH} 20$ or immunized directly with purified recombinant $\mathrm{mPH} 20$ protein fused to maltose-binding protein. Mice treated with either vaccine formulation developed serum antibodies that cross-reacted to a protein band of $55 \mathrm{kDa}$ corresponding to $\mathrm{mPH} 20$ in Western blots of mouse sperm. However, there was no significant reduction in the fertility of males or females compared with control animals with either formulation. We conclude from our data that recombinant $\mathrm{mPH} 20$ is not a useful antigen for inclusion in immunocontraceptive vaccines that target mice.
\end{abstract}

Reproduction (2004) 127 325-334

\section{Introduction}

Mouse PH20 (mPH20), also termed murine sperm adhesion molecule 1 (SPAM-1), is a protein that is present in the male reproductive tract. It is expressed in both the testis and epididymis and is present in sperm and in the luminal fluid of the epididymis (Deng et al. 1999, 2000, Zhang \& Martin-DeLeon 2003a). The PH20 protein is widely conserved among mammals, and homologues have been cloned from many species including guinea pig, where the protein was first identified (Lathrop et al. 1990), rat (Hou et al. 1996), rabbit (Holland et al. 1997), fox (ten Have et al. 1998), pig (Day et al. 2002), monkey and man (Lin et al. 1993).

$\mathrm{PH} 20$ exists as a membrane-bound protein on the surface of sperm (Li et al. 1997) and appears to have several roles in fertilization in various species (Hunnicutt et al. 1996, Cherr et al. 2001, Vines et al. 2001). First, PH20 possesses hyaluronidase activity that facilitates transfer of the sperm through the cumulus layer surrounding the unfertilized egg (Gmachl et al. 1993, Lin et al. 1994). Secondly, PH20 is able to bind directly to the zona pellucida during the early steps of fertilization (Primakoff et al. 1985). This is thought to be due to the ability of $\mathrm{PH} 20$ to bind hyaluronic acid (HA) in the zona pellucida, a process that is independent of its hyaluronidase activity (Hunnicutt et al. 1996, Yudin et al. 1999). Finally, the binding of $\mathrm{PH} 20$ to $\mathrm{HA}$ indirectly triggers an increase in the intracellular calcium of sperm that leads to an increase in the responsiveness of sperm to induction of the acrosome reaction (Cherr et al. 2001).

Immunization with affinity purified $\mathrm{PH} 20$ from guinea pig sperm (gpPH20) has been shown to cause complete and reversible infertility in both female and male guinea pigs after a single dose of antigen (Primakoff et al. 1988, 1997, Tung et al. 1997). In males, immunization with gpPH20 in Freund's adjuvant led to complete infertility due to the loss of normal sperm in the epididymis and associated autoimmune orchitis (Tung et al. 1997), whereas it has been proposed that infertility in females is 
by prevention of sperm-egg binding by $\mathrm{PH} 20$ antibodies (Primakoff et al. 1988).

In order to produce contraceptive vaccines based on sperm that are suitable for vaccinating large numbers of individuals, it is necessary to use recombinant forms of the proteins to generate sufficient quantities of the antigens. However, recombinant sperm proteins are generally less effective than the purified native sperm proteins in inducing an immunocontraceptive response ( $\mathrm{O}^{\prime}$ Rand \& Lea 1997, Naz 1999). In addition, the use of infectious sterilizing agents would avoid the need for direct inoculation and would provide a means for controlling widespread populations of pest animal species through natural transmission of the vaccines (Tyndale-Biscoe 1994).

Recombinant viruses provide one means of delivery of contraceptive antigens and are effective in reducing the fertility of mice (Jackson et al. 1998, Lloyd et al. 2003). These vaccines have employed female gamete antigens and affect the fertility of female mice only. However, the use of a sperm protein such as $\mathrm{PH} 20$ has considerable potential as a recombinant vaccine antigen because it can induce an immunocontraceptive response in male and female animals. This concept has yet to be tested in mice.

The virus vector that has been chosen for the development of immunocontraceptive vaccines for biological control of wild mice in Australia is murine cytomegalovirus (MCMV). This beta-herpesvirus has been selected because it is highly species-specific, it is present in all populations of Australian mice tested to date and multiple strains of it are able to infect a single host animal, indicating that pre-immunity to the virus may not interfere with delivery of a recombinant virus in the field (Shellam 1994, Lloyd et al. 2003). Therefore, in order to test the vaccine potential of $\mathrm{PH} 20$ in mice, we have cloned and characterized $\mathrm{mPH} 20$ from $\mathrm{BALB} / \mathrm{c}$ mice and constructed a recombinant MCMV expressing this protein. The effect of this vaccine on fertility has been tested in male and female mice.

\section{Materials and Methods}

\section{Oligonucleotides}

Oligonucleotides for cDNA synthesis and PCR were synthesized by the Biomolecular Resources Facility (ANU, Canberra, ACT, Australia). Oligonucleotide pairs required for direct annealing to produce double-strand linker DNAs were phosphorylated at the $5^{\prime}$-ends to enable direct cloning into DNA plasmids after annealing without further manipulation, and were synthesized by Life Technologies (Mt Waverly, Victoria, Australia). The cDNA synthesis primer for reverse transcription $5^{\prime}$-GCAAAAATAATAATAATAAT-3' was designed against the $3^{\prime}$-untranslated region of the $\mathrm{mPH} 20$ sequence (GenBank accession number U33958, nucleotides 1897-1878). Oligonucleotide primers for PCR were designed to amplify $1563 \mathrm{bp}$ of cDNA containing the entire coding region of $\mathrm{mPH} 20$. Primers were PH2OFOR
5'-gtggaattcGTGATGGGAGAGTTGAGA-3' (nucleotides 310-327, including the ATG start codon at 313-315), and PH20REV 5'-ggagaattcAAACGCTGTGGGTAGAG-3' (nucleotides 1872-1856, 5 nucleotides downstream of the TAG stop signal). The primers included EcoRI restriction enzyme sites (nucleotides shown in lower case) to facilitate cloning of the PCR product.

\section{PCR cloning of $\mathbf{m P H} 20$}

Polyadenylated RNA was isolated from the testes of inbred BALB/c mice, as previously described (Chomczynski \& Sacchi 1987), and reverse transcribed into cDNA using a TimeSaver cDNA Synthesis Kit (Pharmacia Biotech, Uppsala, Sweden). PCR was conducted in an FTS-320 thermal sequencer (Corbett Research, Lidcombe, Sydney, Australia). The resulting $1581 \mathrm{bp}$ PCR product was subcloned into pBluescriptll KS- to produce plasmid pCMH155 in Escherichia coli strain XL1-Blue (Stratagene, La Jolla, CA, USA). The authenticity of the clone was confirmed by sequencing the entire insert using dye-labelled terminators on a Perkin-Elmer $\mathrm{ABI}$ automated sequencer (Biomolecular Resources Facility, ANU, Canberra, ACT, Australia). DNA sequences were analysed using Geneworks 2.3 (Intelligenetics Inc., Mountain View, CA, USA) and Vector NTI (InforMax, North Bethesda, MD, USA) software. Sequence comparisons were made using the Basic Local Alignment Search Tool (BLAST) (Altschul et al. 1990) and Entrez software (Schuler et al. 1996).

\section{Expression and purification of recombinant $\mathrm{mPH} 20$}

The mPH20 cDNA coding region, minus the first 29 amino acids from the amino terminus that encode a secretory signal sequence to help increase protein yields, was subcloned into the bacterial expression systems pMAL (New England Biolabs, Beverly, MA, USA) and pGEX (Pharmacia Biotech, Uppsala, Sweden). Specifically, an $861 \mathrm{bp} \mathrm{Hinfl/Xbal} \mathrm{DNA} \mathrm{fragment} \mathrm{containing} \mathrm{the} 5^{\prime}$ region of the $\mathrm{mPH} 20 \mathrm{cDNA}$ of $\mathrm{pCMH} 155$ was purified on a $1 \%$ agarose gel. The Hinfl site was end-filled using Klenow enzyme prior to restriction with Xbal to produce a blunt-ended Hinfl/Xbal fragment. Next, a 640 bp Xbal/Sall DNA fragment of $\mathrm{pCMH} 155$, containing the $3^{\prime}$ region of the $\mathrm{mPH} 20 \mathrm{CDNA}$, was purified on a $1 \%$ agarose gel. The two fragments were then inserted into the bacterial expression vector pMal-c cut with Stul and Sall in a threeway ligation to produce $\mathrm{pCMH} 169$ where the $5^{\prime}$ truncated $\mathrm{mPH} 20$ coding region was fused in frame to the maltosebinding protein (MBP) sequence. A 1535 bp EcolcRI/Sall DNA fragment of pCMH169 was subsequently subcloned into pGEX-4T-1 digested with Smal and Sall to produce pCMH309, where the truncated $\mathrm{mPH} 20$ coding region was fused in-frame with the glutathione-S-transferase (GST) sequence. MBP for the control experiments was prepared using the vector pMAL-cR1dH (Hardy et al. 2002a).

Bacterial cell extracts containing recombinant MBP fused to $\mathrm{mPH} 20$ (MBP-mPH20), MBP, GST fused to 
$\mathrm{mPH} 20$ (GST-mPH20) and GST proteins were prepared in E. coli strains BL21-CodonPlus-RIL or XL-1 Blue (Stratagene, La Jolla, CA, USA), as previously described (Hardy \& Holland 1996). MBP proteins were then affinity purified using amylose resin, as previously described (Hardy \& Holland 1996). GST proteins were affinity purified using glutathione sepharose 4B resin (Pharmacia Biotech, Uppsala, Sweden) according to the manufacturer's recommendations.

\section{Construction of MCMV expression plasmid vectors}

The entire $\mathrm{mPH} 20$ coding sequence was cloned into a mammalian gene expression plasmid vector (pCMH149, GenBank accession number AY122060) derived from pCMV-beta (Clontech, GenBank accession number U02451). The plasmid pCMH149 contains a multiple cloning site (MCS) for insertion of genes under the control of the human cytomegalovirus (hCMV) ie1 gene promoter, an intron to enhance gene expression, and a simian virus 40 gene terminator. The $\mathrm{pCMH} 149$ plasmid was produced as follows. The $\beta$-galactosidase gene of plasmid pCMV-beta was excised using Notl and replaced with a multiple cloning site linker, and the unique Sall and EcoRI sites bounding the expression cassette were replaced with Notl linkers. Plasmid pCMH155 was restriction enzyme digested with HindIII, end-filled using Klenow enzyme and re-ligated to produce pCMH156 with the HindIII site removed. A 1612 bp Xmal/Sall fragment of pCMH156 was then cloned into the Xmal/Sall of $\mathrm{pCMH} 149$ to produce the $\mathrm{mPH} 20$ expression plasmid pCMH157.

\section{Construction of MCMV transfer plasmid vectors}

The MCMV transfer plasmid vector $\mathrm{pH} 3 \mathrm{~L}$ contains the entire 7161 bp HindIII L fragment of MCMV strain K181 inserted into plasmid pGEM11 (Lloyd et al. 2003). The $79 \mathrm{bp}$ Hpal fragment of $\mathrm{pH} 3 \mathrm{~L}$ within the MCMV ie2 gene was removed and replaced by a Notl linker to produce $\mathrm{pH} 3 \mathrm{LN}$. Next, the $2672 \mathrm{bp}$ Notl fragment of pCMH157 containing the $\mathrm{mPH} 20$ expression cassette was inserted into $\mathrm{pH} 3 \mathrm{LN}$ (ensuring that $\mathrm{mPH} 20$ gene expression was in the same direction as the MCMV ie2 gene) to produce the MCMV-mPH20 transfer plasmid, pCMH158.

\section{Generation of recombinant (r) MCMV-mPH2O}

The rMCMV strain K181 containing the mPH20 expression cassette ( $\mathrm{rMCMV}-\mathrm{mPH} 20)$ was produced by homologous recombination, as previously described (Lloyd et al. 2003). Briefly, semi-confluent primary mouse embryo fibroblasts (MEF) in six-well trays were co-transfected with 10-50 $\mu \mathrm{g}$ of infectious DNA (MCMV strain K181, substrain RM427+, kindly provided by Prof. E. Mocarski, Stanford University, Stanford, CA, USA) and $2 \mu \mathrm{g}$ pCMH158 linearized with HindIII restriction enzyme. Cells were transfected by a calcium phosphate method using the CellPhect kit (Amersham Pharmacia
Biotechnology UK Ltd, Buckinghamshire, UK) according to the manufacturer's instructions. At the completion of the incubation period, the cells were osmotically shocked with $1 \%$ glycerol in buffered saline with the osmolarity of mouse serum (MOBS, $6.5 \mathrm{mmol} \mathrm{Na} \mathrm{HPO}_{4} / \mathrm{l}, 1.5 \mathrm{mmol}$ $\mathrm{KH}_{2} \mathrm{HPO}_{4} / \mathrm{l}, 2.7 \mathrm{mmol} \mathrm{KCl} / \mathrm{l}$ and $16.8 \mathrm{mmol} \mathrm{NaCl} / \mathrm{l}, \mathrm{pH}$ 7.3) for $1 \mathrm{~min}$. Viruses with the $\mathrm{mPH} 20$ expression cassette inserted by homologous recombination were detected as white plaques after addition of X-gal (5-bromo-4-chloro-3indoyl- $\beta$-D-galactopyranoside) due to replacement of a bacterial $\beta$-galactosidase expression cassette inserted in the ie 2 gene of $\mathrm{RM} 427+$. White plaques were picked and plaque was purified three times before generation of a high titre stock of $\mathrm{MMCMV}-\mathrm{mPH} 20$. The correct insertion of the mPH20 expression cassette into MCMV was confirmed by Southern blot analysis. Viral DNA was prepared from rMCMV-mPH20, as previously described (Lloyd et al. 2003), and restriction fragment length polymorphism was performed using the restriction enzymes HindIII and EcoRV. Fragments were separated on a $0.9 \%$ agarose gel and Southern blots performed using DNA fragments labelled with ${ }^{32} \mathrm{P}-\mathrm{dCTP}$ (Megaprime DNA labelling kit, Amersham) and standard protocols (Sambrook et al. 1989).

\section{Immunization and mating protocols with recombinant proteins}

The Animal Experimentation and Ethics Committee of the CSIRO Division of Sustainable Ecosystems approved all animal experimental procedures involving recombinant proteins, in compliance with the National Health and Medical Research Council of Australia (NHMRC) guidelines. BALB/C mice were obtained from the Animal Resources Centre (Murdoch, Perth, Australia). An i.p. delivery route using Freund's adjuvants was used to generate $\mathrm{mPH} 20$-specific antibodies and to test for antibody responses and antifertility effects of $\mathrm{MBP}-\mathrm{mPH} 20$. This method was chosen as it has previously been shown to induce high antibody titres to self-antigens in mice (Hardy \& Mobbs 1999, Hardy et al. 2002a,b).

$\mathrm{BALB} / \mathrm{c}$ mice (6-8 weeks old) were injected i.p. with $20 \mu \mathrm{g}$ MBP-mPH20 ( $n=10$ female, 5 male) or MBP controls ( $n=10$ female, 5 male) in $100 \mu$ l 50\% Freund's complete adjuvant (FCA) (Sigma). The animals were then boosted i.p. three times with $20 \mu \mathrm{g}$ MBP-mPH2O or MBP in $100 \mu \mathrm{l} 50 \%$ Freund's incomplete adjuvant (FIA) at 2-week intervals. Mice were bled from the suborbital sinus immediately prior to the first injection and again 2 weeks after the final boost. Serum was stored at $-20^{\circ} \mathrm{C}$. Pairs of treated female mice were coupled 2 weeks after the final immunization, when antibody titres were expected to be highest (Hardy \& Mobbs 1999, Hardy et al. 2002a,b), with single males of proven fertility. Pairs of untreated females were added to each of the treated males 2 weeks after the final immunization. All males were removed after 2 weeks, and the females were 
autopsied after a further 2 days to determine the number of live and dead embryos.

\section{Immunization and mating protocols with rMCMV}

The Animal Experimentation and Ethics Committee of the University of Western Australia approved animal experimental procedures with $\mathrm{rMCMV}$, in compliance with the NHMRC guidelines.

BALB/c mice (6-8 weeks old) were inoculated i.p. with $2 \times 10^{4}$ plaque-forming units ( $\mathrm{pfu}$ ) of tissue culturepassaged rMCMV-mPH20 ( $n=6$ male, 6 female) or MOBS diluent containing $0.5 \%$ FCS ( $n=6$ female). Mice were paired immediately with uninfected animals of the opposite sex, and the total number of pups produced by each pair over the following 150 days (from up to seven litters) was counted in order to establish when infertility, if any, was present. All pups were killed immediately after birth by cervical dislocation. All parental mice were bled by cardiac puncture after the completion of the experiment and the serum was stored at $-20^{\circ} \mathrm{C}$.

\section{Assay of antibodies}

Serum IgG antibody levels against recombinant antigens were determined by ELISA using $0.5 \mu \mathrm{g}$ purified recombinant GST-mPH20, MBP-mPH20 or MBP protein per well as antigen, as previously described (Hardy et al. 2003). ELISA results for recombinant proteins are given as absorbance readings at $405 \mathrm{~nm}$. Results for each serum dilution were accepted as positive where the absorbance reading after background subtraction was greater than 0.2 , which was double the maximum absorbance observed for individual pre-immune sera in any of the assays. Serum $\lg G$ antibody responses against MCMV were determined as serum end-point titres by ELISA using 7.5 $\mu \mathrm{g}$ MCMV protein extract per well as antigen, as previously described (Lloyd et al. 2003). ELISA results for MCMV are given as serum end-point titres at $405 \mathrm{~nm}$. Results for each serum dilution were accepted as positive where the absorbance reading was greater than the mean of normal mouse serum plus three times the standard deviation.

\section{Protein extracts and Western blot analysis}

SDS protein extracts of mouse caudal epididymal sperm were produced as previously described (Hardy \& Mobbs 1999). Polyacrylamide gel electrophoresis and immunoblot analyses were conducted as previously described (Laemmli 1970), and proteins were transferred to Polyscreen PVDF transfer membranes (NEN DuPont, Boston, MA, USA) and probed with mouse sera diluted 1:100, followed by peroxidase-conjugated goat anti-mouse $\lg \mathrm{G}$ secondary antibody diluted according to the manufacturer's recommendations (Bio-Rad Laboratories, Hercules, CA, USA).

\section{Statistical analysis}

Results are presented as means \pm S.E.M. Data were analysed by Student's $t$-test using SYSTAT (Evanston, IL, USA). A value of $P<0.05$ was accepted as significant.

\section{Results}

\section{Characterization of $\mathbf{m P H} 20$}

The mPH20 (SPAM1) was cloned using reverse transcriptase PCR from the testis of BALB/C mice (submitted to GenBank, accession number AY228460). Several independent PCR products were sequenced and shown to have the identical sequence. The PCR product contained the entire coding region for $\mathrm{mPH} 20$ and included 24 nucleotides of $3^{\prime}$ non-coding sequence. The sequence was identical to that present in three exons of a genomic mouse clone from chromosome 6 of strain C57BL/6) (GenBank accession number AC127559), but differed slightly from the cDNA sequences of a $\mathrm{C} 57 \mathrm{BL} / 6 \mathrm{~J}$ and an unidentified mouse strain. The $\mathrm{mPH} 20$ coding region of $\mathrm{BALB} / \mathrm{c}$ mice has a single nucleotide difference leading to one amino acid change relative to the sequence for SPAM1 cDNA isolated from a C57BL/6) mouse (GenBank accession number AK005638) and four nucleotide differences, leading to two amino acid changes, relative to the sequence from the undescribed strain of mouse (GenBank accession number U33958). Differences in the AY228460 mPH20 cDNA sequence relative to $\mathrm{U} 33958$ were nt $603=\mathrm{T}$ (vs C), nt 856-857 = GA (vs AG, expressed as glutamate vs arginine respectively), and nt $883=\mathrm{T}$ (vs $\mathrm{C}$, expressed as phenylalanine vs leucine respectively). The difference in AY228460 relative to AK005638 was nt $1799=A$ (vs G, expressed as histidine vs arginine respectively).

\section{Properties of MBP-mPH20}

Mouse $\mathrm{PH} 20$ was expressed with the $\mathrm{N}$-terminus (from amino acid 30) fused to the C-terminus of maltose-binding protein (MBP-mPH20) in E. coli strains XL1-Blue and BL21-CodonPlus-RIL. The predicted size of the MBP$\mathrm{mPH} 20$ fusion protein was 864 aa with an estimated molecular mass of $97 \mathrm{kDa}$. Initial studies of MBP-mPH20 protein expression were conducted in XL1-Blue cells, but the size of the recombinant protein was less than predicted, and it also appeared degraded. In contrast, the apparent molecular mass of the MBP-mPH20 protein on SDS-PAGE gels $(97 \mathrm{kDa})$ was similar to the predicted size when expressed in BL21-CodonPlus-RIL cells (Fig. 1). Recombinant MBP-mPH20 protein prepared from BL21CodonPlus-RIL cells was used in immunization and fertility trials.

\section{Properties of recombinant GST-mPH2O}

Mouse $\mathrm{PH} 20$ was expressed with the $\mathrm{N}$-terminus (from amino acid 30) fused to the carboxyl terminus of 


\section{Lane}

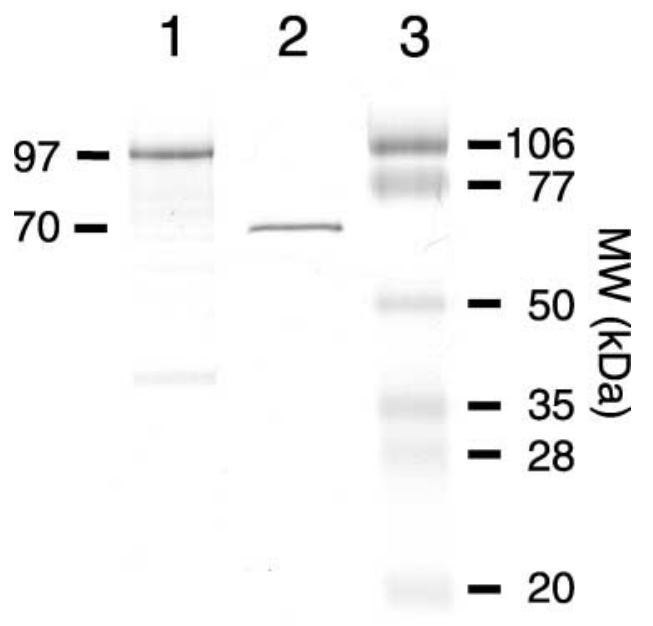

Figure 1 SDS-PAGE of affinity purified recombinant $\mathrm{mPH} 20$ proteins. Proteins were reduced and separated on a $12 \%$ SDS-PAGE gel and stained with Coomassie brilliant blue. Lane 1, MBP-mPH20; lane 2, GST-mPH20; lane 3, molecular mass markers. MBP-mPH20: mouse $\mathrm{PH} 20$ fused to maltose-binding protein; GST-mPH20: mouse PH20 fused to glutathione- $S$-transferase.

glutathione-S-transferase (GST-mPH20) in E. coli strain BL21-CodonPlus-RIL. The predicted size of the GST$\mathrm{mPH} 20$ fusion protein was 724 aa with an estimated molecular mass of $83 \mathrm{kDa}$. The majority of the

\section{Lane}

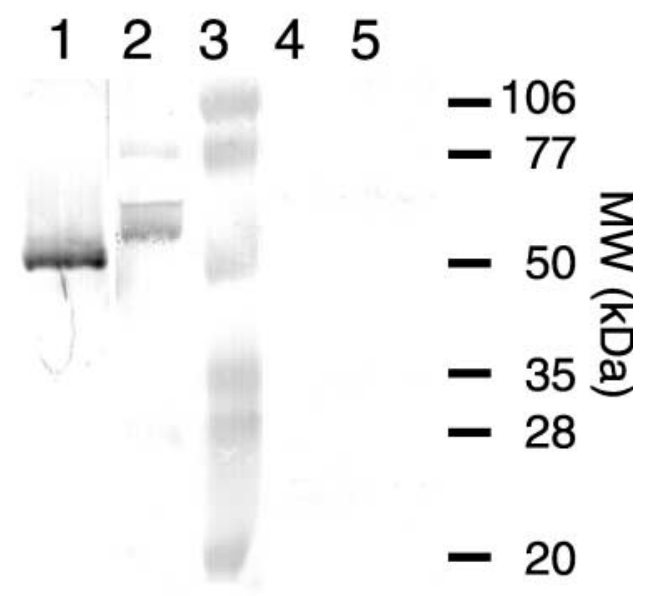

Figure 2 Antibodies to $\mathrm{mPH} 20$ detected by Western blot. Protein extracts were reduced and separated on a $12 \%$ SDS-PAGE gel and transferred to PVDF membranes. Lanes 1, 4: SDS extracts of mouse sperm; lanes 2, 5: purified GST-mPH20. Membranes were probed with sera (diluted $1: 100$ ) raised in mice and visualized using horseradish peroxidase-conjugated goat anti-mouse IgG antibodies. Lanes 1, 2: MBP$\mathrm{mPH} 20$ immune sera; lanes 4, 5 pre-immune sera; lane 3: molecular mass markers. MBP-mPH20: mouse $\mathrm{PH} 20$ fused to maltose-binding protein; GST-mPH20: mouse $\mathrm{PH} 20$ fused to glutathione-S-transferase. recombinant GST-mPH20 protein appeared as a $70 \mathrm{kDa}$ band on SDS-PAGE gels, $13 \mathrm{kDa}$ less than predicted from the primary amino acid sequence (Fig. 1). However, some proteins were also detected at 60 and $80 \mathrm{kDa}$ on Western blots (Fig. 2). Recombinant GST-mPH20 protein prepared from BL21-CodonPlus-RIL cells was used for ELISA and in Western blot analyses.

\section{Restriction fragment length polymorphism of rMCMV expressing $\mathrm{mPH} 20$}

Restriction fragment length polymorphism and Southern blot were used to verify the structure of the rMCMV$\mathrm{mPH} 20$ virus (Fig. 3). Restriction digests were conducted using either HindIII or EcoRV, and probed using a $2672 \mathrm{bp}$ Notl DNA fragment of $\mathrm{pCMH} 158$ containing the mPH2O cDNA. Insertion of the $\mathrm{mPH} 20$ gene expression cassette in the correct orientation into the ie2 region of the HindlII $\mathrm{L}$ fragment of the MCMV strain K181 genome (expression in the same direction as the disrupted ie2 gene) was
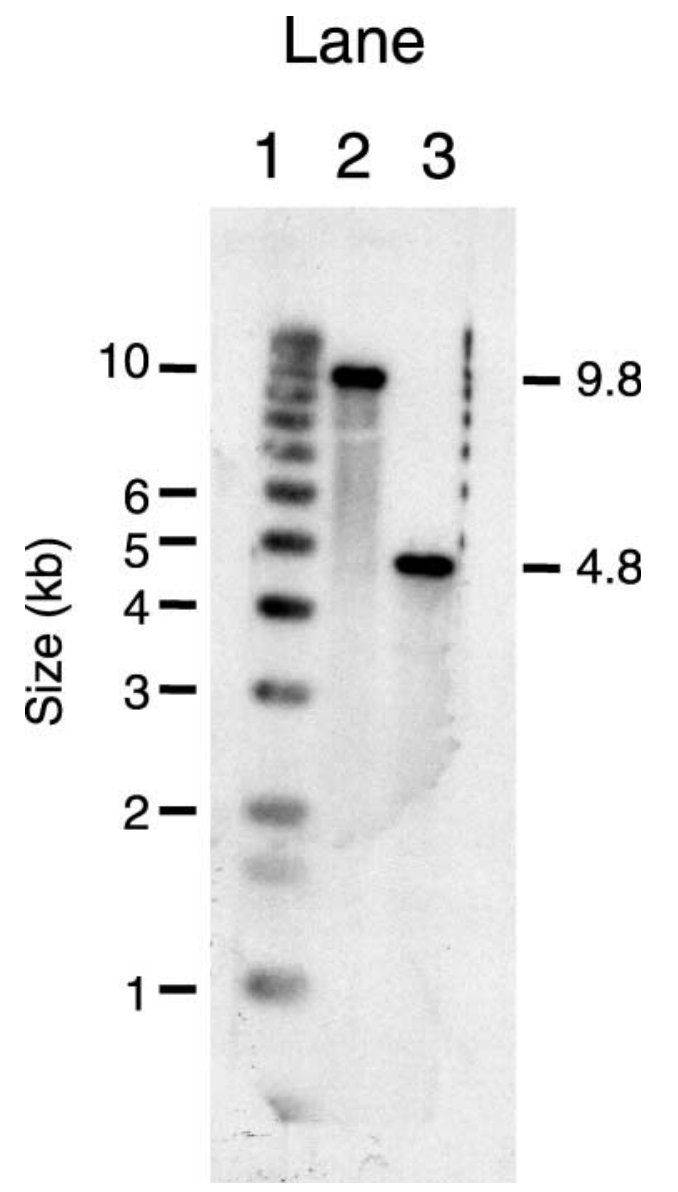

Figure 3 Restriction fragment length polymorphism analysis of rMCMV-mPH20 viral DNA. Restriction enzyme digests of purified rMCMV-mPH20 DNA were separated on a $0.9 \%$ agarose gel, transferred to nylon membranes and probed with ${ }^{32} \mathrm{P}$-labelled $\mathrm{mPH} 20$ DNA. Lane 1, 1 kb DNA marker; lane 2, HindIII digest; lane 3, EcoRV digest. rMCMV-mPH20: recombinant murine cytomegalovirus expressing $\mathrm{mPH} 20$. 
confirmed by detection of DNA fragments with the anticipated sizes for both the HindIII (9762 bp) and EcoRV (4835 bp) digests of the viral DNA (Fig. 3).

\section{Serum IgG responses of mice immunized with MBP-mPH20}

Sera from mice inoculated with MBP-mPH20 were tested for the presence of cross-reactive IgG antibodies to recombinant GST-mPH20 by ELISA (Fig. 4) and to recombinant GST-mPH20 and sperm on Western blots (Table 1). No cross-reacting antibodies were detected by either ELISA (absorbance <0.1) or Western blot (no visible bands) against MBP, GST or GST-mPH20 in pre-immune serum samples diluted 1:100. In addition, no cross-reacting IgG antibodies against GST were detected by either ELISA or Western blot from any of the sera of treated mice at 2 weeks after the final immunization. There was considerable variation in the $\mathrm{mPH} 20$-specific serum antibody responses of individual $\mathrm{BALB} / \mathrm{C}$ mice immunized with MBP-mPH20 using both detection methods.

The sera of all male and female mice immunized with MBP-mPH2O contained cross-reacting IgG antibodies to GST-mPH20 (absorbance $>0.2$ ) at 2 weeks after the final inoculation as determined by ELISA (Fig. 4). Absorbances at serum dilutions of 1:100 (the minimum

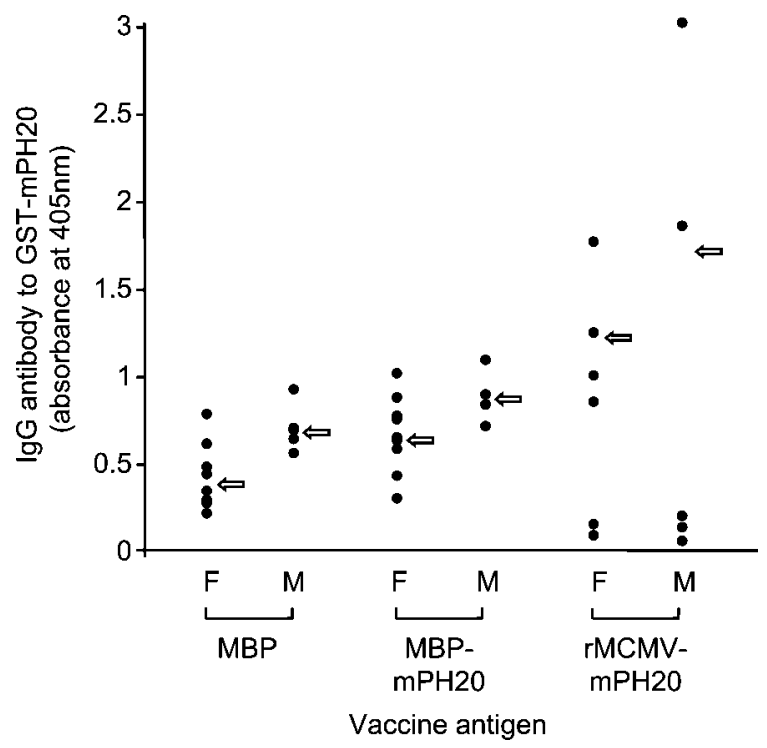

Figure 4 Antibodies to $\mathrm{mPH} 20$ detected by ELISA. Sera (diluted 1:100) from male and female mice were tested for the presence of $\mathrm{mPH} 20$-specific IgG antibodies by ELISA either 2 weeks after the final immunization (MBP and MBP-mPH20 treated mice), or 150 days after inoculation ( $\mathrm{rMCMV}-\mathrm{mPH} 20$ treated mice) using purified recombinant GST-mPH20 as detection antigen. GST-mPH20: mouse $\mathrm{PH} 20$ fused to glutathione- $S$-transferase; MBP: maltose-binding protein; MBP-mPH20: mouse PH20 fused to MBP; rMCMV-mPH20: recombinant murine cytomegalovirus expressing mouse $\mathrm{PH} 20 ; \mathrm{F}$, females; $M$, males. Arrows indicate the mean of absorbance values at $405 \mathrm{~nm}$ from responder (absorbance >0.2) mice for each of the six groups of sera.
Table 1 Prevalence of seropositive sera by Western blot in BALB/C mice treated with recombinant $\mathrm{mPH} 20$ vaccines.

\begin{tabular}{llrrrr}
\hline & & \multicolumn{2}{c}{\begin{tabular}{c} 
Total \\
\cline { 3 - 5 } number
\end{tabular}} & & \multicolumn{2}{c}{ Number of seropositive mice ${ }^{\mathrm{a}}$} \\
\cline { 5 - 6 } Treatment & Sex & of mice & Sperm & GST-mPH20 & $\begin{array}{c}\text { Sperm }+ \\
\text { GSTmPH20 }\end{array}$ \\
\hline MBP & Female & 10 & 10 & 0 & 0 \\
MBP & Male & 5 & 2 & 0 & 0 \\
MBP-mPH20 & Female & 10 & 10 & 6 & 6 \\
MBP-mPH20 & Male & 5 & 4 & 4 & 4 \\
rMCMV-mPH20 & Female & 6 & 1 & 4 & 1 \\
rMCMV-mPH20 & Male & 6 & 1 & 3 & 0 \\
\hline
\end{tabular}

${ }^{a}$ Sera were collected 2 weeks after the final boost (MBP, MBP-

$\mathrm{mPH} 20$ ) or 150 days after infection (rMCMV-mPH20). Mice were scored as seropositive if bands were visible on Western blots probed with 1:100 diluted sera.

dilution tested) against GST-mPH20 ranged from 0.28 to 0.99 for females and 0.72 to 1.05 for males, with mean ODs of $0.61 \pm 0.06$ s.E.M. for females (MBP control $0.37 \pm 0.06)$ and $0.85 \pm 0.07$ S.E.M. for males (MBP control $0.66 \pm 0.06$ ). All mice responded strongly to the MBP carrier protein, and antibodies to MBP (absorbance $>0.2$ ) were present in the sera of all MBP-mPH20 and MBP immunized mice at serum dilutions of up to 1:100 000 . Cross-reacting $\operatorname{lgG}$ antibodies to both GST-mPH2O and sperm protein extracts were detected on Western blots in the sera (diluted 1:100) of $6 / 10$ female and $4 / 5$ male mice immunized with MBP-mPH20 (Table 1). All positive sera from the mice cross-reacted strongly to a $55 \mathrm{kDa}$ protein in sperm extracts and up to three bands with apparent molecular masses of 60,70 and approximately $80 \mathrm{kDa}$ in purified GST-mPH20 (Fig. 2). None of the sera from control mice immunized with MBP alone crossreacted to GST-mPH20 on Western blots. However, 12/15 of the immune serum samples from the MBP immunized mice cross-reacted with an $\sim 55 \mathrm{kDa}$ band in Western blots of sperm extract, although the band was faint (result not shown). Pre-immune sera from the MBP-mPH20 and MBP control mice did not react to either antigen by Western blot.

\section{Serum IgG responses of mice inoculated with rMCMV-mPH20}

Sera from mice inoculated with rMCMV-mPH2O were tested for the presence of cross-reactive $\lg G$ antibodies to recombinant GST-mPH20 by ELISA (Fig. 4) and to recombinant GST-mPH20 and sperm proteins on Western blots (Table 1$)$. Sera from several mice $(2 / 6$ males and $2 / 6$ females) did not contain $\operatorname{lgG}$ antibodies to $\mathrm{mPH} 20$ using any of the detection systems at 150 days post-inoculation, and serum from one male contained antibodies that crossreacted only to sperm. However, cross-reacting antibodies were detected to GST-mPH20 by ELISA (absorbance $>0.2)$ in the sera of the remaining male (3/6) and female (4/6) mice (Fig. 4) at 150 days post-inoculation. The mean 
absorbances at serum dilutions of 1:100 against GST$\mathrm{mPH} 20$ for these seropositive mice were $1.20 \pm 0.20$ s.E.M. for females and $1.68 \pm 0.22$ S.E.M. for males. The sera from the seven mice that reacted with GST-mPH2O by ELISA also reacted with GST-mPH20 by Western blot (Table 1 ). However, IgG antibodies that cross-reacted with a sperm protein band of $55 \mathrm{kDa}$ on Western blots were detected only in the sera of two mice (one female and one male). Most mice (6/6 male and 5/6 female) inoculated with rMCMV-mPH20 produced detectable IgG antibody responses against MCMV by ELISA at 150 days after inoculation. The males produced generally higher levels of IgG antibodies (mean titre of 1:670 \pm 218 S.E.M. with a range of $1: 20-1: 1280)$ than the five positive females (mean titre of 1:22 \pm 7 S.E.M. with a range of 1:10-1:40).

\section{Fertility of mice immunized with MBP-mPH2O}

There was no significant reduction in the mean litter sizes of female mice immunized with MBP-mPH20 and mated to untreated males, or of untreated females mated to male mice immunized with MBP-mPH20, compared with the control mice immunized with MBP alone (Table 2). The fertility data for the control MBP-treated group of female mice have been reported previously (Hardy et al. 2002a).

There was no correlation between fertility and the level of antibody response, either against sperm protein extracts by Western blot or against recombinant GST-mPH20 by ELISA of mice immunized with MBP-mPH20 (result not shown). The only significant difference $(P=0.02)$ was that MBP-treated males sired significantly fewer pups $(n=26)$ than the MBP-mPH20-treated males $(n=61)$ (Table 2).

\section{Fertility of mice immunized with rMCMV-mPH2O}

There was no significant reduction in the fertility, mean litter sizes or total number of pups produced over 150 days for female BALB/c mice inoculated with rMCMV-mPH20 compared with females inoculated with diluent alone (Table 3). Likewise, there was no reduction in the fertility, mean litter sizes or total number of pups in untreated females mated with rMCMV-mPH20-inoculated males compared with diluent controls. All six male and six female BALB/C mice that were inoculated with $\mathrm{rMCMV}$ $\mathrm{mPH} 20$ and five of six female BALB/c mice treated with MOBS diluent produced litters during the 150 days after inoculation (Table 3).

There was no correlation between the number of pups born to individual parents and the presence or absence of IgG antibody responses against mPH20 either by ELISA or by Western blot in mice inoculated with rMCMV-mPH20 (result not shown).

\section{Discussion}

The development of $\mathrm{PH} 20$ as the basis for contraceptive wildlife vaccines relies on the generation of appropriate sources of antigen and delivery mechanisms (Holland et al. 1997 , Pomering et al. 2002). Two different antigen and delivery formulations of recombinant mouse $\mathrm{PH} 20$ $(\mathrm{mPH} 20$, SPAM-1) were therefore produced as part of an effort to develop immunocontraceptive vaccines for use as biological control agents for mice. The first vaccine was in the form of repeated direct injections of mice with $\mathrm{mPH} 20$ produced in a bacterial expression system (MBP$\mathrm{mPH} 20$ ), and the second was a single inoculation of mice

Table 2 Fertility of BALB/c mice immunized with recombinant MBP-mPH20 protein.

\begin{tabular}{llccccc}
\hline Antigen & Sex & $\begin{array}{c}\text { Number } \\
\text { of mice }\end{array}$ & $\begin{array}{c}\text { Number of } \\
\text { fertile mice }\end{array}$ & $\begin{array}{c}\text { Number of } \\
\text { implantations }\end{array}$ & $\begin{array}{c}\text { Number of } \\
\text { viable embryos }\end{array}$ & $\begin{array}{c}\text { Litter size } \\
\text { (mean } \pm \text { S.E.M.) }\end{array}$ \\
\hline MBP-mPH20 & Female & 10 & 8 & 45 & 45 & $4.5 \pm 1.3$ \\
MBP & Female & 10 & 7 & 55 & 52 & $61^{\mathrm{b}}$ \\
MBP-mPH20 & Male & 5 & 5 & 27 & 2.3 & $2.1 \pm 1.2^{\mathrm{c}}$ \\
MBP & Male & 5 & 2 & $2.6 \pm 1.2^{\mathrm{c}}$ \\
\hline
\end{tabular}

${ }^{\text {a }}$ Fertility data for the group of MBP-treated females have been published (Hardy et al. 2002a).

${ }^{\mathrm{b}}$ Embryos produced from ten untreated females mated to five treated males.

${ }^{\mathrm{c}}$ There was significant difference between the mean number of pups sired by male mice treated with MBP and MBP-mPH20 $(P=0.02)$. There was no significant difference between the mean litter sizes of the treated and control groups of female mice.

Table 3 Fertility of BALB/c mice inoculated with $\mathrm{rMCMV}-\mathrm{mPH} 20$.

\begin{tabular}{|c|c|c|c|c|c|c|c|}
\hline Inoculum & Sex & $\begin{array}{l}\text { Number } \\
\text { of mice }\end{array}$ & $\begin{array}{l}\text { Number of } \\
\text { fertile mice }\end{array}$ & Total litters & Live pups & Total pups $^{\mathrm{a}}$ & $\begin{array}{c}\text { Litter size } \\
(\text { mean } \pm \text { S.E.M. })^{a}\end{array}$ \\
\hline rMCMV-mPH20 & Female & 6 & 6 & 32 & 201 & 207 & $6.5 \pm 0.5$ \\
\hline $\mathrm{rMCMV}-\mathrm{mPH} 20$ & Male & 6 & 6 & 30 & 203 & 207 & $6.9 \pm 0.4$ \\
\hline MOBS & Female & 6 & 5 & 26 & 156 & 158 & $6.1 \pm 0.5$ \\
\hline
\end{tabular}

\footnotetext{
${ }^{a}$ Total number of pups produced over 150 days after inoculation, including dead pups. No significant difference in production of pups was present between the treated and control groups of mice. 
with a recombinant MCMV expressing $\mathrm{mPH} 20$ (rMCMV$\mathrm{mPH} 20$ ). Neither recombinant $\mathrm{mPH} 20$ vaccine formulation significantly reduced the fertility of either female or male mice.

Several factors may have contributed to the inability of the rMCMV-mPH20 or MBP-mPH20 to cause infertility in mice. In particular, native $\mathrm{PH} 20$ proteins may have antigenic epitopes with immunocontraceptive potential not present in either of the recombinant forms used in this study. For example, native $\mathrm{PH} 20$ is proteolytically cleaved late in sperm maturation during passage in the epididymis in rodents such as guinea pigs (Phelps et al. 1990), rats (Seaton et al. 2000) and mice (Deng et al. 1999). In addition, modifications to $\mathrm{N}$-linked oligosaccharides on native $\mathrm{mPH} 20$ have also been reported during the passage of mouse sperm through the epididymis (Deng et al. 1999). Neither of these modifications is likely to have occurred to the recombinant proteins. It is therefore possible that such epididymis-specific modifications to $\mathrm{PH} 2 \mathrm{O}$ are required to provide B-cell epitopes associated with the immunocontraceptive effects seen in guinea pigs with native gpPH20 isolated from sperm (Primakoff et al. 1988, 1997, Tung et al. 1997). In this respect, there is evidence that antisera produced by $\mathrm{BALB} / \mathrm{c}$ mice to $\mathrm{MBP}-\mathrm{mPH} 20$ and rMCMV-mPH20 cross-reacted to only one, partially glycosylated form of $\mathrm{mPH} 20$. The mice treated with the MBP-mPH20 and rMCMV-mPH20 vaccine formulations that were seropositive on Western blots of BALB/c caudal sperm all recognized a band with apparent molecular mass of $\sim 55 \mathrm{kDa}$. This is smaller than the principal band of $\sim 67 \mathrm{kDa}$ previously reported by others for $\mathrm{mPH} 20$ (SPAM-1), but similar to a minor band present in extracts of acrosome intact caudal sperm (Thaler \& Cardullo 1995, Deng et al. 1999, 2000, Zhang \& Martin-DeLeon 2001, Zhang \& Martin-DeLeon 2003a). The discrepancy in the estimated sizes of the $\mathrm{mPH} 20$ sperm protein may be explained by differences in the SDS-PAGE protocols and molecular mass markers used, although the major band detected in extracts of acrosome-reacted sperm and partially de-glycosylated sperm is reported to be $56 \mathrm{kDa}$ (Deng et al. 1999).

Interestingly, an $\sim 55 \mathrm{kDa}$ band in sperm was also recognized by sera in some mice immunized with $\mathrm{MBP}$ alone. Although we cannot discount the possibility that the cross-reaction of antibodies to sperm was due to MBPspecific antibodies in the mice, the intensity of the reaction on Western blots was considerably greater for mice immunized with MBP-mPH20 than for those immunized with MBP alone (result not shown). This suggests that $\mathrm{mPH} 20$-specific antibodies were indeed produced by the MBP-mPH20-immunized mice and that the antibodies in MBP-immunized mice that reacted with the sperm extract were to another protein of similar molecular mass. The cross-reactivity of rabbit serum containing MBP-specific antibodies to sperm has also been noted in rabbits (Hardy et al. 1997).
The MBP-mPH20 and rMCMV-mPH20 vaccines induced qualitatively different $\mathrm{mPH} 20$-specific antibodies in the mice when tested against non-denatured (ELISA) or denatured (Western blot) $\mathrm{mPH} 20$ proteins. For example, individual mice inoculated with rMCMV-mPH20, but not MBP-mPH20, appeared to be either responders $(n=7)$ or non-responders to GST-mPH20 $(n=5)$. Only 3/6 males and 4/6 females inoculated with rMCMV-mPH20 exhibited GST-mPH20-specific antibodies at serum dilutions of 1:100. In addition, antibodies that cross-reacted to both GST-mPH20 and sperm on Western blots were present in the sera of most mice (10/15) immunized with MBP$\mathrm{mPH} 20$, compared with only a single mouse inoculated with rMCMV-mPH20 (Table 1). The different immune responses can be attributed to differences in the structural features of the two recombinant $\mathrm{mPH} 20$ antigens. In particular, post-translational modifications, such as glycosylation of $\mathrm{mPH} 20$, may have taken place in the virally expressed protein, but not in the bacterially produced fusion protein (Benz \& Schmidt 2002). However, regardless of the theoretical differences in the glycosylation of the $\mathrm{PH} 20$ protein in the two vaccine formulations, an immunocontraceptive effect was not apparent for either. This again may indicate that the native $\mathrm{mPH} 20$ protein could contain critical immunocontraceptive B-cell epitopes that were not present in the recombinant forms.

Lack of immunocontraceptive effect for $\mathrm{PH} 20$ has also been reported for bacterially produced rabbit $\mathrm{PH} 20$ in rabbits (Holland et al. 1997), and in this animal, the inability to cause sterility was directly attributed to insufficient $\mathrm{PH} 20$ antibodies in the male and female reproductive tracts (Pomering et al. 2002) rather than to absence of critical epitopes in the protein. Therefore, there may have been insufficient $\mathrm{mPH} 20$ antibodies generated in the reproductive tracts to cause infertility in mice using the immunization regimes of the present study. In this respect, effects on fertility of female BALB/c mice immunized with another recombinant sperm antigen (sp56) were seen only after the mice had received five, and not three, boosts (the regime used for MBP-mPH20) with the protein in Freund's incomplete adjuvant (Hardy \& Mobbs 1999).

In guinea pigs, infertility following immunization with a single injection of native gpPH20 was reversible (Primakoff et al. 1988, 1997, Tung et al. 1997). These studies were conducted in outbred guinea pigs, and although all the animals developed high titres of $\mathrm{PH} 20$-specific antibodies, recovery of fertility could not be correlated with any reduction in antibody titres. Therefore, it is possible that appropriate $\mathrm{PH} 20$-specific cellular immune responses are required for development of contraceptive responses and that the inbred BALB/c mice used in the present study did not produce these responses. In this respect, antisera raised in BALB/C mice against BALB/C sperm have previously been shown to contain far fewer sperm-reactive antibodies than antisera raised in BALB/C mice against sperm from other strains of mice (Xu \& Anderson 1987). Conversely, significant immune reactions and effects on 
fertility in mice have been shown to occur after passive transfer of leucocytes from mice immunized with whole mouse sperm, but only when the leucocytes were produced in a non-identical strain (Tinneberg et al. 1980). Examination of the GenBank database revealed that amino acid polymorphisms are present between $\mathrm{mPH} 20$ sequences from different mouse strains, and it is possible that immunization of $\mathrm{BALB} / \mathrm{c}$ mice with recombinant $\mathrm{mPH} 20$ proteins derived from another strain of mice could improve cellular immunogenicity and produce a contraceptive effect.

The strong immunocontraceptive effect reported for gpPH20 in guinea pigs (Primakoff et al. 1988, 1997, Tung et al. 1997), but not seen for mice in this study, could reflect more fundamental differences in the biological role of $\mathrm{PH} 20$ between the two species. It has been shown recently that $\mathrm{mPH} 20$ gene knockout mice remain fully fertile and that $\mathrm{mPH} 20$ is dispensable for fertilization and sperm penetration of cumulus in mice (Baba et al. 2002). Although this does not preclude the ability of an anti$\mathrm{PH} 20$ immune response to disrupt fertilization, it suggests that $\mathrm{PH} 20$ may not play as essential a role in fertilization in mice as it does in guinea pigs. $\mathrm{PH} 20$ appears to be expressed in the male reproductive tract only of several species, including guinea pig (Primakoff et al. 1988), man (Lin et al. 1993) and rabbit (Holland et al. 1997), whereas mPH20 (SPAM-1) expression is more widespread. PH20 protein and transcripts have been identified in testis, epididymis and kidney cells (Deng et al. 1999, 2000, Zhang \& Martin-DeLeon 2001, Zhang \& Martin-DeLeon 2003a), as well as in the female reproductive tract (Zhang \& MartinDeLeon 2003b). The more widespread expression of $\mathrm{mPH} 20$ in mice could also affect the ability to break tolerance to $\mathrm{PH} 20$ by active immunization in this species.

Finally, the lack of contraceptive effect with $\mathrm{mPH} 20$ is unlikely to be due to limitations of the delivery systems. In contrast to the present data with $\mathrm{mPH} 20$, the female-specific antigen $\mathrm{mZP3}$ induced infertility in female $\mathrm{BALB} / \mathrm{C}$ mice when they were treated using the same vaccine approaches used for $\mathrm{mPH} 20$ (Hardy et al. 2003, Lloyd et al. 2003). In particular, rMCMV-mZP3 induced long-lasting sterility in almost $100 \%$ of female mice after a single inoculation (Lloyd et al. 2003).

In conclusion, fertility control using disseminating virally vectored contraceptive vaccines has the potential to provide an effective means for reducing pest animal populations, such as those of house mice, which cause significant economic damage in southern Australia. However, we have demonstrated that recombinant $\mathrm{mPH} 20$ appears to be unsuitable for use in contraceptive vaccines for mice when delivered either as a protein produced in bacteria or by rMCMV.

\section{Acknowledgements}

The authors would like to acknowledge the expert technical assistance of Kathy Williams, Nicole Harvey, Juliet Fisher,
Rebecca Knee and Kelly Debono. This work was supported by funds provided by the Australian Grains Research and Development Corporation (CSV16) and the Australian government's Cooperative Research Centres Program. Clive Sweet acknowledges the support of a Wellcome Trust Travelling Fellowship.

\section{References}

Altschul SF, Gish W, Miller W, Myers EW \& Lipman DJ 1990 Basic local alignment search tool. Journal of Molecular Biology 215 403-410.

Baba D, Kashiwabara S, Honda A, Yamagata K, Wu Q, Ikawa M, Okabe M \& Baba T 2002 Mouse sperm lacking cell surface hyaluronidase $\mathrm{PH}-20$ can pass through the layer of cumulus cells and fertilize the egg. Journal of Biological Chemistry 277 30310-30314.

Benz I \& Schmidt MA 2002 Never say never again: protein glycosylation in pathogenic bacteria. Molecular Microbiology 45 267-276.

Cherr GN, Yudin Al \& Overstreet JW 2001 The dual functions of $\mathrm{GPI}$-anchored $\mathrm{PH}-20$ : hyaluronidase and intracellular signaling. Matrix Biology 20 515-525.

Chomczynski P \& Sacchi N 1987 Single-step method of RNA isolation by acid guanidinium thiocyanate-phenol-chloroform extraction. Analytical Biochemistry 162 156-159.

Day AE, Quilter CR, Sargent CA \& Mileham AJ 2002 Characterization of the porcine sperm adhesion molecule gene SPAM1 expression analysis, genomic structure, and chromosomal mapping. Animal Genetics 33 211-214.

Deng X, Czymmek K \& Martin-DeLeon PA 1999 Biochemical maturation of Spam1 $(\mathrm{PH}-20)$ during epididymal transit of mouse sperm involves modifications of $\mathrm{N}$-linked oligosaccharides. Molecular Reproduction and Development 52 196-206.

Deng X, He Y \& Martin-DeLeon PA 2000 Mouse Spam1 (PH-20): evidence for its expression in the epididymis and for a new category of spermatogenic-expressed genes. Journal of Andrology 21 $822-832$.

Gmachl M, Sagan S, Ketter S \& Kreil G 1993 The human sperm protein $\mathrm{PH}-20$ has hyaluronidase activity. FEBS Letters 336 545-548.

Hardy CM \& Holland MK 1996 Cloning and expression of recombinant rabbit fertilin. Molecular Reproduction and Development 45 107-116.

Hardy CM \& Mobbs KJ 1999 Expression of recombinant mouse sperm protein sp56 and assessment of its potential for use as an antigen in an immunocontraceptive vaccine. Molecular Reproduction and Development 52 216-224.

Hardy CM, Clarke HG, Nixon B, Grigg JA, Hinds LA \& Holland MK 1997 Examination of the immunocontraceptive potential of recombinant rabbit fertilin subunits in rabbit. Biology of Reproduction $\mathbf{5 7}$ 879-886.

Hardy CM, Pekin J \& ten Have J 2002a Mouse-specific immunocontraceptive polyepitope vaccines. Reproduction Supplement $\mathbf{6 0}$ 19-30.

Hardy CM, ten Have JF, Mobbs KJ \& Hinds LA 2002b Assessment of the immunocontraceptive effect of a zona pellucida 3 peptide antigen in wild mice. Reproduction, Fertility, and Development 14 $151-155$.

Hardy CM, ten Have JF, Pekin J, Beaton S, Jackson RJ \& Clydesdale G 2003 Contraceptive responses of mice immunized with purified recombinant mouse zona pellucida subunit 3 (mZP3) proteins. Reproduction 126 49-59.

Holland MK, Andrews J, Clarke H, Walton C \& Hinds LA 1997 Selection of antigens for use in a virus-vectored immunocontraceptive vaccine: PH-20 as a case study. Reproduction, Fertility, and Development 9 117-124.

Hou ST, Ma A, Jones R \& Hall L 1996 Molecular cloning and characterization of rat sperm surface antigen 2B1, a glycoprotein implicated in sperm-zona binding. Molecular Reproduction and Development 45 193-203. 
Hunnicutt GR, Primakoff P \& Myles DG 1996 Sperm surface protein $\mathrm{PH}-20$ is bifunctional: one activity is a hyaluronidase and a second, distinct activity is required in secondary sperm-zona binding. Biology of Reproduction 55 80-86.

Jackson RJ, Maguire DJ, Hinds LA \& Ramshaw IA 1998 Infertility in mice induced by a recombinant ectromelia virus expressing mouse zona pellucida glycoprotein 3. Biology of Reproduction $\mathbf{5 8}$ $152-159$.

Laemmli UK 1970 Cleavage of structural proteins during the assembly of the head of bacteriophage T4. Nature 227 680-685.

Lathrop WF, Carmichael EP, Myles DG \& Primakoff P 1990 cDNA cloning reveals the molecular structure of a sperm surface protein, $\mathrm{PH}-20$, involved in sperm-egg adhesion and the wide distribution of its gene among mammals. Journal of Cell Biology 111 2939-2949.

Li MW, Cherr GN, Yudin AI \& Overstreet JW 1997 Biochemical characterization of the $\mathrm{PH}-20$ protein on the plasma membrane and inner acrosomal membrane of cynomolgus macaque spermatozoa. Molecular Reproduction and Development 48 356-366.

Lin Y, Kimmel LH, Myles DG \& Primakoff P 1993 Molecular cloning of the human and monkey sperm surface protein PH-20. PNAS 90 $10071-10075$.

Lin Y, Mahan K, Lathrop WF, Myles DG \& Primakoff P 1994 A hyaluronidase activity of the sperm plasma membrane protein $\mathrm{PH}-20$ enables sperm to penetrate the cumulus cell layer surrounding the egg. Journal of Cell Biology 125 1157-1163.

Lloyd ML, Shellam GR, Papadimitriou JM \& Lawson MA 2003 Immunocontraception is induced in BALB/c mice inoculated with murine cytomegalovirus expressing mouse zona pellucida 3. Biology of Reproduction 68 2024-2032.

Naz RK 1999 Vaccine for contraception targeting sperm. Immunological Reviews 171 193-202.

O'Rand MG \& Lea IA 1997 Designing an effective immunocontraceptive. Journal of Reproductive Immunology 36 51-59.

Phelps BM, Koppel DE, Primakoff P \& Myles DG 1990 Evidence that proteolysis of the surface is an initial step in the mechanism of formation of sperm cell surface domains. Journal of Cell Biology 111 $1839-1847$.

Pomering M, Jones RC, Holland MK, Blake AE \& Beagley KW 2002 Restricted entry of IgG into male and female rabbit reproductive ducts following immunization with recombinant rabbit PH-20. American Journal of Reproductive Immunology 47 174-182.

Primakoff P, Hyatt H \& Myles DG 1985 A role for the migrating sperm surface antigen $\mathrm{PH}-20$ in guinea pig sperm binding to the egg zona pellucida. Journal of Cell Biology $1012239-2244$.

Primakoff P, Lathrop W, Woolman L, Cowan A \& Myles D 1988 Fully effective contraception in male and female guinea pigs immunized with the sperm protein PH-20. Nature 335 543-546.

Primakoff P, Woolman-Gamer L, Tung KS \& Myles DG 1997 Reversible contraceptive effect of $\mathrm{PH}-20$ immunization in male guinea pigs. Biology of Reproduction 56 1142-1146.

Sambrook J, Fritsch EF \& Maniatis T 1989 Molecular Cloning: A Laboratory Manual, 2nd edn. New York: Cold Spring Harbor Laboratory Press.
Schuler GD, Epstein JA, Ohkawa H \& Kans JA 1996 Entrez: molecular biology database and retrieval system. Methods in Enzymology $266141-162$.

Seaton GJ, Hall L \& Jones R 2000 Rat sperm 2B1 glycoprotein ( $\mathrm{PH} 20)$ contains a $\mathrm{C}$-terminal sequence motif for attachment of a glycosyl phosphatidylinositol anchor. Effects of endoproteolytic cleavage on hyaluronidase activity. Biology of Reproduction 62 1667-1676.

Shellam GR 1994 The potential of murine cytomegalovirus as a viral vector for immunocontraception. Reproduction, Fertility, and Development 6 401-409.

ten Have J, Beaton S \& Bradley MP 1998 Cloning and characterization of the cDNA encoding the $\mathrm{PH} 20$ protein in the European red fox Vulpes vulpes. Reproduction, Fertility, and Development 10 165-172.

Thaler CD \& Cardullo RA 1995 Biochemical characterization of a glycosylphosphatidylinositol-linked hyaluronidase on mouse sperm. Biochemistry 34 7788-7795.

Tinneberg H, Birke R \& Mettler L 1980 Effect on fertility of female mice of the transfer of lymphocytes from females previously immunized with mouse spermatozoa. Journal of Reproduction and Fertility $\mathbf{5 8} 469-473$.

Tung KS, Primakoff P, Woolman-Gamer L \& Myles DG 1997 Mechanism of infertility in male guinea pigs immunized with sperm $\mathrm{PH}$ 20. Biology of Reproduction 56 1133-1141.

Tyndale-Biscoe CH 1994 Virus-vectored immunocontraception of feral mammals. Reproduction, Fertility, and Development 6 $281-287$.

Vines CA, Li MW, Deng X, Yudin AI, Cherr GN \& Overstreet JW 2001 Identification of a hyaluronic acid (HA) binding domain in the $\mathrm{PH}-20$ protein that may function in cell signaling. Molecular Reproduction and Development $60542-552$.

Xu C \& Anderson DJ 1987 Differences in immunogenicity indicating polymorphism of sperm antigens from mice of different inbred strains. Journal of Reproductive Immunology 11 167-180.

Yudin AI, Vandevoort CA, Li MW \& Overstreet JW 1999 PH-20 but not acrosin is involved in sperm penetration of the macaque zona pellucida. Molecular Reproduction and Development $\mathbf{5 3}$ $350-362$.

Zhang H \& Martin-Deleon PA 2001 Mouse epididymal Spam1 $(\mathrm{PH}-20)$ is released in vivo and in vitro, and Spam1 is differentially regulated in testis and epididymis. Biology of Reproduction 65 1586-1593.

Zhang H \& Martin-DeLeon PA 2003a Mouse epididymal Spam1 $(\mathrm{PH}-20)$ is released in the luminal fluid with its lipid anchor. Journal of Andrology 24 51-58.

Zhang H \& Martin-DeLeon PA 2003b Mouse Spam1 (PH-20) is a multifunctional protein: evidence for its expression in the female reproductive tract. Biology of Reproduction 69 446-454.

Received 23 September 2003

First decision 14 November 2003

Accepted 24 November 2003 